\title{
Development of Solar Grade (SoG) Silicon
}

\author{
Final Report for DOE SBIR Phase II \\ Contract Number DE-FG02-04ER83928
}

US Department of Energy

9800 South Cass Avenue

Argonne, IL 60439

Covering Period:

July 11, 2005 through October 18, 2007

January 16, 2008

Prepared by

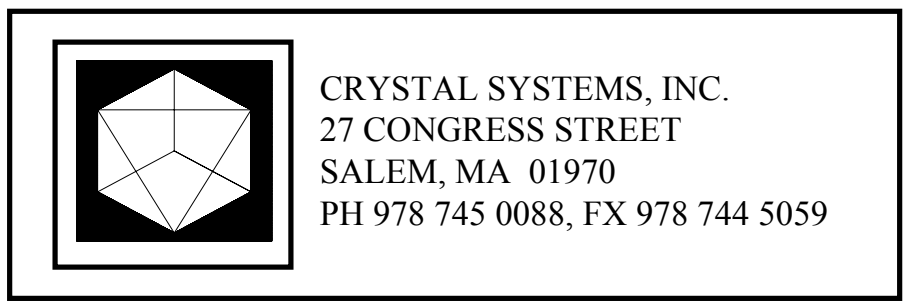


Final Report for DOE SBIR Phase II, Contract Number DE-FG02-04ER83928

Crystal Systems, Inc., 27 Congress Street, Salem, MA 01970

\section{Development of Solar Grade (SoG) Si}

\section{TABLE OF CONTENTS}

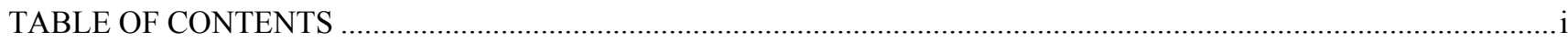

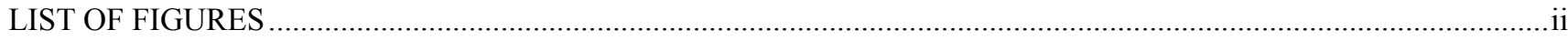

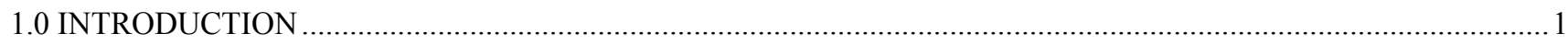

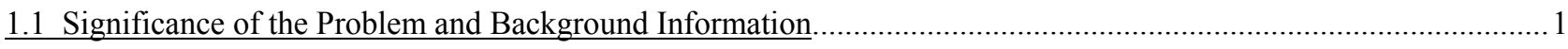

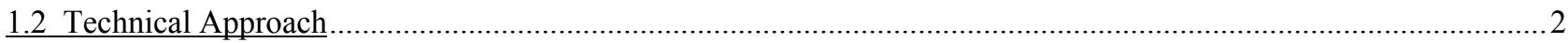

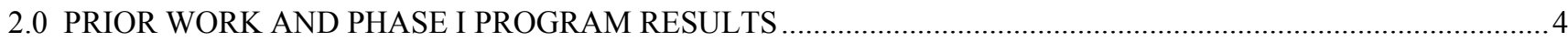

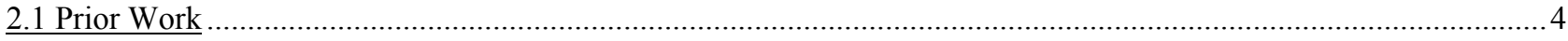

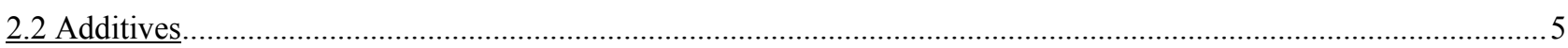

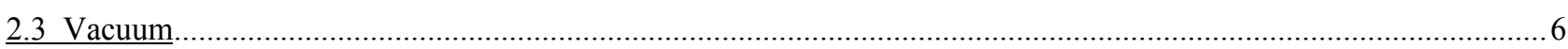

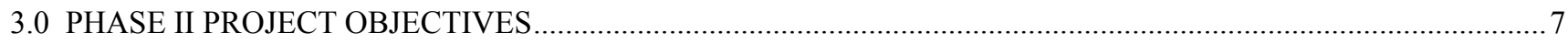

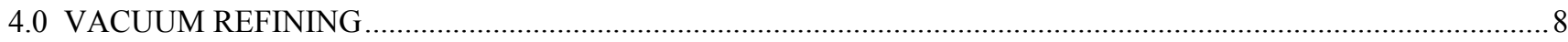

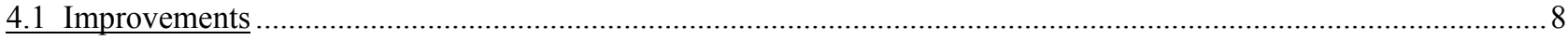

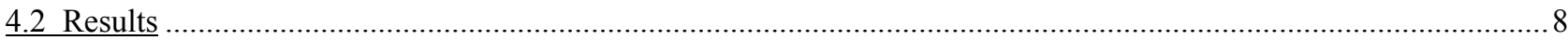

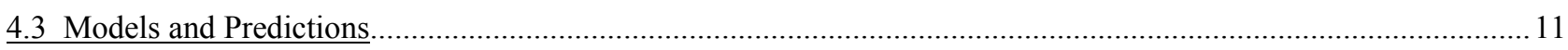

4.4 Cold Finger

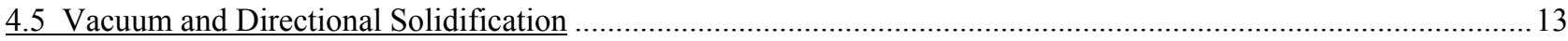

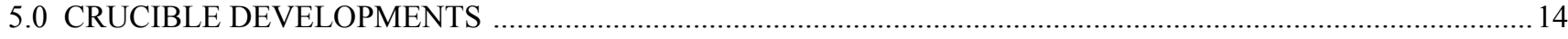

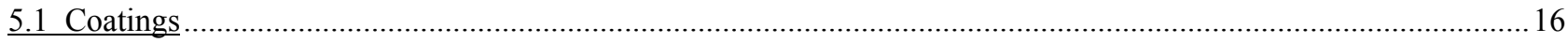

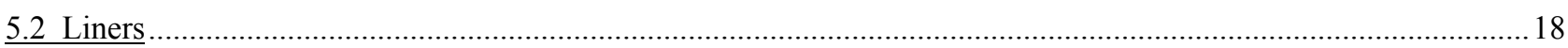

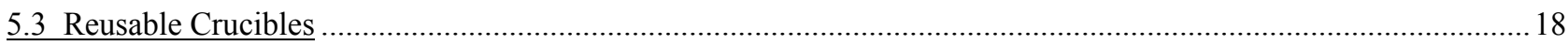

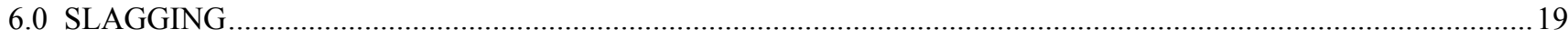

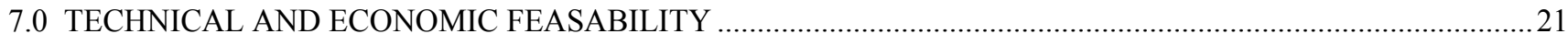

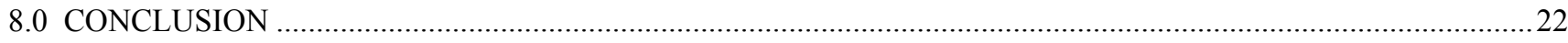

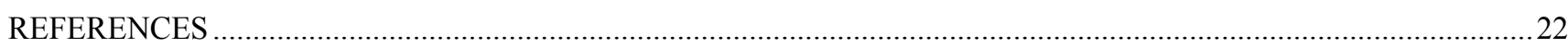


Final Report for DOE SBIR Phase II, Contract Number DE-FG02-04ER83928

Crystal Systems, Inc., 27 Congress Street, Salem, MA 01970

\section{LIST OF FIGURES}

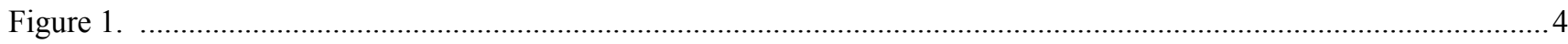

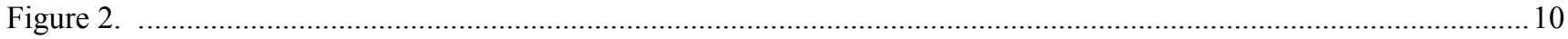

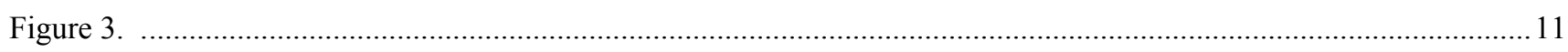

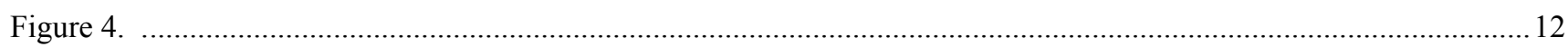

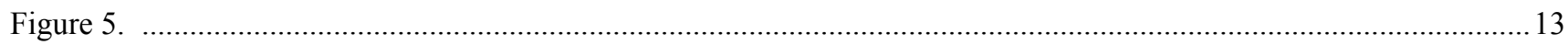

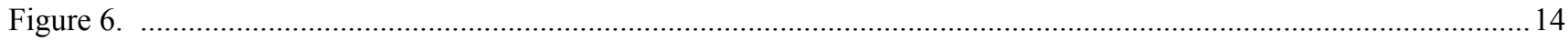

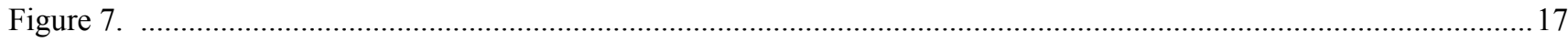

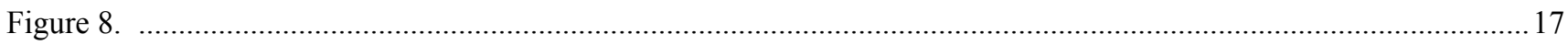

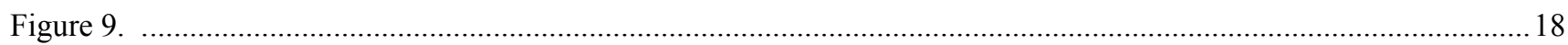

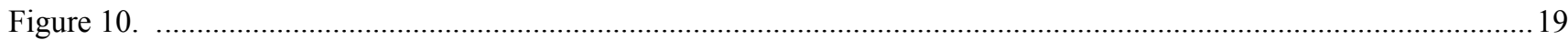


Final Report for DOE SBIR Phase II, Contract Number DE-FG02-04ER83928

Crystal Systems, Inc., 27 Congress Street, Salem, MA 01970

\subsection{INTRODUCTION}

\subsection{Significance of the Problem and Background Information}

The global market for photovoltaics (PV) is growing at a phenomenal rate, and is expected to be worth $\$ 12.9$ billion in 2007 , and increase to $\$ 32.3$ billion by 2012 . The industry grew by $44 \%$ in 2005 , and $58 \%$ in 2006 , and is projected to have grown $53 \%$ in 2007 , despite serious problems with silicon supply ${ }^{1}$. The growth has been driven by the global demand for energy, the potential problems of climate change, the renewable features of solar energy and improvements in PV technology and materials.

The PV industry has been meeting the challenge of commercial viability by lowering prices and increasing capacity to meet demands. In doing so, it has lowered costs and increased efficiency to sustain this phenomenal growth. However, as has been predicted, it is now limited from continued growth by the availability of low-cost solar grade $(\mathrm{SoG})$ silicon feedstock in large quantities. This shortage was anticipated, and was the motivation for this program. The goal was to further develop low-cost technology to remove boron (B), phosphorus (P), and aluminum (Al), to produce SoG silicon at low cost by upgrading inexpensive, widely available MG (MG) silicon.

Before 2004, the silicon feedstock requirements for the PV industry could all be met by excess capacity, rejects and scraps of polysilicon from the semiconductor industry. Since then, the PV industry has needed to buy virgin polysilicon, but was still able to be supplied by the excess capacity of the polysilicon industry. Last year, however, the demand for silicon by PV equaled the demand by electronics, and next year is expected to surpass it. Although major silicon manufacturers have announced plans to increase supply of polysilicon, these sources won't come online until 2009 time frame. Also, there is doubt whether the supply of polysilicon will be ramped up at the rate needed to meet the PV industry's rapidly expanding needs. This shortage has been reflected in a punishing price increase in silicon. The contract price paid for in recent times for polysilicon is over $\$ 70 / \mathrm{kg}$. This price will likely never go back to the unrealistically low levels of $\$ 20 / \mathrm{kg}$ that was available to fuel PV growth in prior years when there was an oversupply of polysilicon. This is yet another reason why a lower price method of producing SoG silicon than the conventional polysilicon processes is needed by the PV industry.

As large and as rapid as PV growth has been, there are forecasts of even larger growth to come. PV generated electricity will reach price parity with grid electricity in the next 3 to 7 years at current rates of cost decline in PV. When parity is reached, unbounded growth of PV has been predicted ${ }^{2}$. Demand for SoG silicon in the long run could grow to many hundreds of thousands of metric tons per year, rivaling the entire US production of metallurgical grade (MG) silicon.

All of these point to the continuing and growing need to secure a low cost, high volume sources of SoG silicon. Upgrading widely available, inexpensive MG silicon represents such a technique to provide a high volume of low cost SoG silicon. A further desirable feature of producing SoG silicon from MG silicon is the much lower investment compared to the high investment capital costs for electronic grade (EG) polysilicon plants that requires a long payback time and adds risk to the decision to make such a plant. 
Final Report for DOE SBIR Phase II, Contract Number DE-FG02-04ER83928

Crystal Systems, Inc., 27 Congress Street, Salem, MA 01970

\subsection{Technical Approach}

Commercially available MG silicon typically contains 10,000 ppmw impurities, whereas EG silicon is of very high purity (low ppb impurities). SoG silicon should be roughly in the range of $1 \mathrm{ppm}$ total impurities, which is hundreds to a thousand times less pure than EG Si, but approximately 10,000 times more pure than MG silicon. The MG silicon produced by carbothermic reduction of silica in a submerged electrode arc furnace is abundantly available at low cost $(\sim \$ 1.50 / \mathrm{kg})$, but is unsuitable for PV applications. The EG silicon is produced specifically for the semiconductor industry using multiple distillations of silanes. This material is expensive ( $>\$ 60 / \mathrm{kg}$ stable price), and at the same time it is of a higher purity than is required for PV industry. At the present time, contract prices are in the $\$ 70 / \mathrm{kg}$ range, and the spot market has been reported as high as $\$ 400 / \mathrm{kg}$ - essentially the same price as silver! However, the current process for producing EG silicon produces unnecessarily pure material for PV purposes. What is needed is a technique that can produce silicon in the range of 1 ppm total impurities. The specifications for abundantly available MG, EG, and SoG silicon are shown in Table 1.

Table 1. Impurity concentrations (ppma) in MG, EG and SoG silicon.

\begin{tabular}{|c|c|c|c|}
\hline Impurity & MG & EG & SoG \\
\hline $\mathbf{B}$ & $37-45$ & 0.0002 & 0.5 \\
\hline $\mathbf{A l}$ & $1,200-4,000$ & $<0.0008$ & $<0.1$ \\
\hline $\mathbf{P}$ & $27-30$ & 0.0008 & 0.05 \\
\hline $\mathbf{C a}$ & 590 & $<0.003$ & $<0.1$ \\
\hline $\mathbf{T i}$ & $150-200$ & $<0.003$ & $<0.1$ \\
\hline $\mathbf{V}$ & $100-200$ & $<0.003$ & $<0.1$ \\
\hline $\mathbf{C r}$ & $50-140$ & $<0.003$ & $<0.1$ \\
\hline $\mathbf{M n}$ & $70-80$ & $<0.003$ & $<0.1$ \\
\hline $\mathbf{F e}$ & $1,600-3,000$ & $<0.010$ & $<0.1$ \\
\hline $\mathbf{N i}$ & $40-80$ & $<0.010$ & $<0.1$ \\
\hline $\mathbf{C u}$ & $24-90$ & $<0.003$ & $<0.1$ \\
\hline $\mathbf{Z r}$ & 30 & $<0.010$ & $<0.003$ \\
\hline $\mathbf{M o}$ & $<10$ & & \\
\hline
\end{tabular}

The simplest approach for developing SoG silicon that is of sufficient purity, but is lower cost and more easily scaled than current EG methods, is to upgrade MG silicon. It has been recognized that, other than $\mathrm{B}, \mathrm{P}$ and $\mathrm{Al}$, most impurities can be reduced sufficiently using directional solidification. Upgrading MG silicon in the past has included using high-purity starting materials during MG silicon production, hydro-, pyro-metallurgical refining, high-vacuum refining and plasma-arc reduction of impurities prior to directional solidification of molten charge ${ }^{3-19}$. None of these processes has reached commercialization because B and $\mathrm{P}$ could only be removed using special processes that were not cost 
Final Report for DOE SBIR Phase II, Contract Number DE-FG02-04ER83928

Crystal Systems, Inc., 27 Congress Street, Salem, MA 01970

effective. It is generally agreed that if an effective $\mathrm{B}$ and $\mathrm{P}$ reduction process can be developed that is also cost-effective, upgrading of MG silicon will be the best approach to producing low-cost SoG silicon.

An experimental Heat Exchanger Method (HEM) furnace with additional features of processing silicon with controlled atmosphere, gas blowing, addition of slags, etc. was used for the experimental program. Most of the metallic impurities are effectively reduced by directional solidification due to their low segregation coefficient in silicon. Therefore, it is recognized that directional solidification plays a very important role in purification of low segregating impurities and using an HEM furnace is a good choice as it is recognized as one of the best directional solidification systems in the world. Assuming that the low segregation impurities will be reduced by directional solidification, the Phase I and Phase II programs concentrated on reduction of $\mathrm{B}, \mathrm{P}$ and $\mathrm{Al}$ in MG silicon to achieve the technical objectives of the program.

A schematic of a process for upgrading MG silicon to SoG silicon is shown in Figure 1 where molten silicon from a submerged direct arc reduction furnace is poured into a refining furnace. The refining furnace will use a combination of gas blowing and slagging, and vacuum. After refining, the charge would then undergo a directional solidification to achieve reduction of non-volatile and/or low segregation impurities. If the molten silicon after refining is poured into molds, it will increase the throughput of the refining furnace and the crucible could be reused thereby reducing the equipment and expendable materials costs. Such a process could be used in an industrial plant and with large charge sizes. 


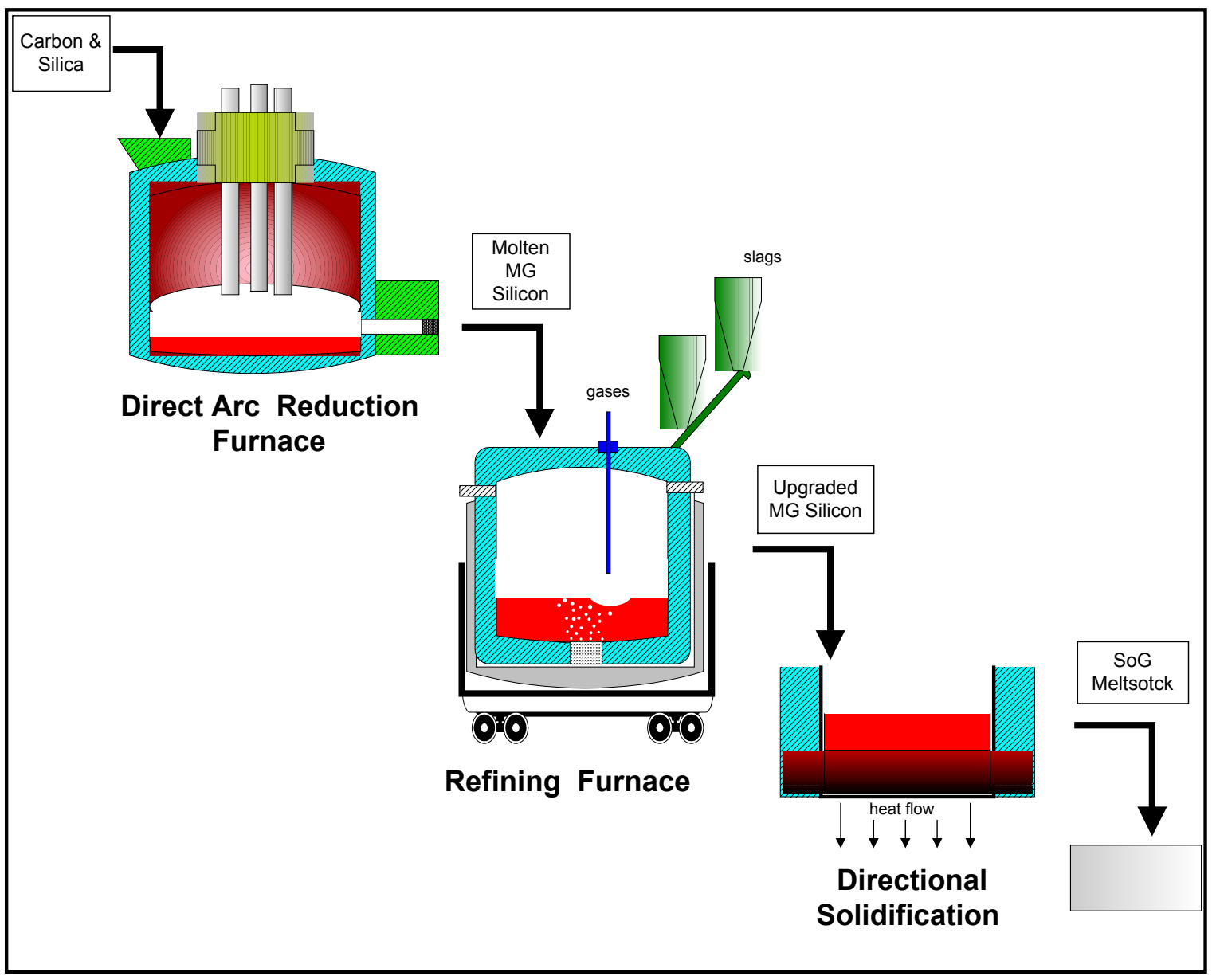

Figure 1. Schematic diagram of SoG silicon production by upgrading MG silicon. The process begins with selected raw materials to make the MG silicon in the Direct Arc Reduction (DAR) furnace. This molten or directionally solidified material is further refined in the refining furnace using vacuum, slagging and gas treatments. This step would be combined, or tightly coupled, with directional solidification to result in SoG silicon meltstock.

\subsection{PRIOR WORK AND PHASE I PROGRAM RESULTS}

\subsection{Prior Work}

The problem of development of SoG silicon goes back to the 1970's when a number of approaches were pursued through a Low-Cost silicon Solar Array program managed by the Jet Propulsion Laboratory. While most of the approaches utilized chemical purification, a program at Dow Corning involved upgrading of $\mathrm{MG} \mathrm{Si}^{3}$. The emphasis of this program was on using high purity starting materials to achieve a higher purity upgraded MG (UMG) silicon that could be the basis for SoG silicon. Thereafter, a number of approaches were pursued in Europe, Japan and the United States involving companies such as Wacker ${ }^{13}$, Bayer ${ }^{16}$, Solarex ${ }^{11}$, Elkem/Exxon ${ }^{14}$, Kawasaki Steel ${ }^{18}$, etc. with an aim to upgrade MG silicon and produce SoG silicon. None of these approaches have been commercialized. 
Final Report for DOE SBIR Phase II, Contract Number DE-FG02-04ER83928

Crystal Systems, Inc., 27 Congress Street, Salem, MA 01970

Approaches to upgrade MG silicon have been mainly handicapped by difficulties in reducing $\mathrm{B}, \mathrm{P}$ and $\mathrm{Al}$ levels. Most of the other contaminants are effectively removed by directional solidification. Therefore, if low-cost simple processes for B and P reduction can be developed, it can result in costeffective production of SoG silicon without the need for setting up a large capital-intensive production plan. The Phase I program (details of experiments shown below in Table 2) was to develop alternative approaches for $\mathrm{B}, \mathrm{P}$, and $\mathrm{Al}$ reduction that are cost effective in large sizes either by themselves or in combination with other processes so that low-cost SoG silicon can be produced on a commercial basis.

Boron removal technology compatible with upgrading MG silicon was developed at Crystal Systems during a PVMaT program supported by NREL. It was demonstrated ${ }^{20}$ that $\mathrm{B}$ could be reduced to 0.3 ppma, $\mathrm{P}$ to $<10 \mathrm{ppma}$ and all other impurities to $<0.1 \mathrm{ppma}$. This process was applied to highly doped EG Si, and the B concentration was reduced from 300 ppma to $0.3 \mathrm{ppma}^{21}$. Test solar cells fabricated from this refined material showed $7.3 \%, 12.5 \%$ and $13.4 \%$ efficienctes $^{22}$.

This boron-removal technology was licensed to Dow Corning in 2005. Prior to and during this SBIR PHASE I program, Crystal Systems worked cooperatively with Dow Corning to utilize this B removal technology to produce SoG silicon on a commercial basis. Some of this work has been under the auspices of a joint venture Advanced Technology Program (ATP), funded by NIST ${ }^{23}$, involving GE Energy, Dow Corning, and Crystal Systems. Based on Dow Corning's operations, it has not been easy to duplicate the efficiency of B reduction in large batches in a commercial plant. A major focus of this SBIR program, therefore, has been to develop alternative approaches for B reduction so that low-cost SoG silicon can be produced on a commercial basis.

\subsection{Additives}

Prior work at Crystal Systems had shown that addition of some metallic elements to a charge of molten MG silicon could reduce the effective segregation coefficient of $\mathrm{P}$ from 0.35 to $<0.1$. Therefore, it was proposed to add rare-earth elements/compounds to molten silicon and evaluate if these rare-earth ions form borides and phosphides, which can be removed by volatilization, segregation or phase separation during directional solidification. In addition, it was intended to add scavengers to the molten silicon bath to aid $\mathrm{B}, \mathrm{P}$, and $\mathrm{Al}$ reduction from MG silicon. The scavengers were expected to form complexes that increase the volatility, leaving behind purer silicon. Even if the vacuum conditions were insufficient for scavengers to remove impurities by volatilization, it was expected that such additions could have other effects, such as, decreasing the segregation coefficient, or precipitating out a second phase that would sequester the impurity. This effect had been seen and previously used in other systems, such as with $\mathrm{Cu}$ and $\mathrm{Al}$. (ref).

In order to evaluate the effect of rare-earth elements, Ce was added to various silicon charges, and after reaction with molten silicon the melt was directionally solidified. In order to evaluate the effect of the added ions on removal of B or P, two different high purity silicon meltstocks for the initial experiments were used, one containing $\mathrm{B}$ as dopant and the other, $\mathrm{P}$ as dopant. In MG Si, additional to $\mathrm{B}$ and $\mathrm{P}$ there are other impurities. Hence, it is difficult to decipher the real effect of the rare-earth ions on the removal of $\mathrm{B}$ and $\mathrm{P}$. 
Final Report for DOE SBIR Phase II, Contract Number DE-FG02-04ER83928

Crystal Systems, Inc., 27 Congress Street, Salem, MA 01970

Other elements were similarly added to silicon charges to act as scavengers, which could form volatile compounds and be removed from the charge. Other possible effects of these components could be to complex with the impurities, thus decreasing the segregation coefficient, or to form second phases to sequester the impurity. One of the candidates used as a scavenger was tungsten. Although some very interesting results were obtained indicating a large reduction in B by ICP, these results were not confirmed by resistivity measurements later made on the ingot. Another drawback was the high levels of $\mathrm{W}$ that remained in the ingot, despite a favorable segregation coefficient. Tungsten is a particularly deleterious element in silicon for PV purposes, and the focus shifted to other elements, including $\mathrm{Re}$ and $\mathrm{Cu}$.

The addition of $\mathrm{Cu}$ led to very poor segregation, making it difficult to evaluate the effects of $\mathrm{Cu}$ on the segregation coefficients of the elements.

Overall the effects of additions were unclear. Although there were indications of strong effects, the drawbacks of unacceptably high levels of the element and/or the high cost of the additions in the quantities that might be needed caused the focus to shift during the Phase II program. One of the additions, however led to the slagging approach, which has produced some extremely interesting reductions in $\mathrm{B}$ and $\mathrm{P}$, as discussed more fully later.

\section{$\underline{2.3 \text { Vacuum }}$}

Also during the Phase I SBIR program, emphasis was placed on developing an alternate crucible that could be used under vacuum conditions for effective $\mathrm{P}$ and $\mathrm{Al}$ removal both with and without additives. It was shown that, with the right crucible, and processing, vacuum is an effective way to remove $\mathrm{P}$ and $\mathrm{Al}$ from $\mathrm{MG}$ silicon in an industrial environment at low cost. However, even using a suitable crucible during the Phase I, it was difficult to achieve sufficient vacuum levels for effective $\mathrm{P}$ reduction. It was realized that for the Phase II program, a better vacuum system would be needed, and the furnace would need to be overhauled and sealed more robustly than had been done.

In Table 2, runs MG3-87 and MG3-90 both were attempts to remove P by vacuum. It can be seen that effective P removal could be achieved - from an original value of $0.39 \mathrm{ppmw}$ to $0.065 \mathrm{ppmw}$ in MG3-87, and from an original value of $15 \mathrm{ppmw}$ to $0.23 \mathrm{ppmw}$ in MG3-90 - even though the furnace used for this experiment was set up with a mechanical pump vacuum. With a diffusion pump and improved vacuum the P removal will be more effective. The data from MG3-90 also shows that in addition to $\mathrm{P}$ removal there was significant reduction in $\mathrm{Al}$ and $\mathrm{B}$, which are also difficult elements to purify. The Al was reduced from $370 \mathrm{ppmw}$ to $0.065 \mathrm{ppmw}$ and the B concentration was reduced from 12 ppmw to 5.8 ppmw. 
Final Report for DOE SBIR Phase II, Contract Number DE-FG02-04ER83928

Crystal Systems, Inc., 27 Congress Street, Salem, MA 01970

\begin{tabular}{|c|c|c|c|c|c|c|c|c|c|c|c|}
\hline $\begin{array}{l}\text { Run } \\
\text { No. }\end{array}$ & $\begin{array}{l}\text { Crucibl } \\
\text { e Type }\end{array}$ & $\begin{array}{l}\text { Mass } \\
\mathrm{Si}(\mathrm{kg})\end{array}$ & $\begin{array}{l}\mathrm{Si} \\
\text { Type }\end{array}$ & $\begin{array}{l}\text { Mass } \\
\text { Additive } \\
\text { (gm) }\end{array}$ & Additive & $\begin{array}{c}\text { Pre-Run } \\
\text { P } \\
\text { (ppmw) }\end{array}$ & $\begin{array}{c}\text { Post-run P } \\
\text { pre DS } \\
\text { (ppmw) }\end{array}$ & $\begin{array}{c}\text { Pre-run } \\
\text { B } \\
\text { (ppmw) }\end{array}$ & $\begin{array}{c}\text { Post-run B } \\
\text { pre DS } \\
\text { (ppmw) }\end{array}$ & $\begin{array}{l}\mathrm{P} \text { or } \mathrm{B} \text {, from } \\
\text { resistivity, net } \\
\text { uncompensated } \\
\text { for MG Si } \\
\quad(\mathrm{ppmw})\end{array}$ & Comments \\
\hline 79 & $\mathrm{SiO}_{2}$ & 19.46 & B & 251.03 & W & - & NA & $\sim 120$ & 4.2 & $133 \mathrm{~B}$ & W $2.7 \%$ by ICP \\
\hline 80 & $\mathrm{SiO}_{2}$ & 17.6 & $\mathrm{P}$ & 227.29 & W & $\sim 1$ & 0.28 & - & & $3.1 \mathrm{P}$ & $\begin{array}{c}31 \text { ppmw W by } \\
\text { GDMS }\end{array}$ \\
\hline 81 & $\mathrm{SiC}$ & 2 & $\mathrm{P}$ & 0.72 & $\mathrm{CaF} 2$ & $\sim 1$ & & - & & - & Leaked \\
\hline 82 & $\mathrm{SiC}$ & 1 & $\mathrm{P}$ & & C & $\sim 1$ & NA & - & NA & - & Leaked \\
\hline 83 & $\mathrm{SiO}_{2}$ & 11.46 & B & 21.39 & $\mathrm{Ce}$ & - & & $\sim 120$ & $10(12.5)$ & $121.7 \mathrm{~B}$ & $\begin{array}{c}0.35 \text { and } 4.6 \\
\text { ppmw Ce (ICP) }\end{array}$ \\
\hline 84 & $\mathrm{SiO}_{2}$ & 11.48 & P & 28.51 & $\mathrm{Ce}$ & $\sim 1$ & NA & - & & - & Leaked \\
\hline 85 & $\mathrm{SiO}_{2}$ & 6 & $\mathrm{P}$ & 15.21 & $\mathrm{Ce}$ & $\sim 1$ & $0.28(0.8)$ & - & $0.17,0.28$ & & $\begin{array}{c}\text { GDMS } \\
\text { Resistivities } \\
\mathrm{N} \text { to } \mathrm{P}\end{array}$ \\
\hline 86 & $\mathrm{Si}_{3} \mathrm{~N}_{4}$ & 0.25 & $\mathrm{P}$ & - & & $\sim 1$ & NA & - & - & - & Leaked \\
\hline 87 & graphite & 4.82 & $\mathrm{P}$ & - & none & 0.39 & $\begin{array}{c}0.065 \\
(0.186)\end{array}$ & 0.065 & $\begin{array}{c}0.77(0 . \\
96)\end{array}$ & $1.2 \mathrm{~B}$ & Vacuum only \\
\hline 88 & $\mathrm{SiO}_{2}$ & 4 & $\mathrm{P}$ & $\begin{array}{c}1000 \\
2000 \\
500\end{array}$ & $\begin{array}{c}\mathrm{CaF} 2, \\
\mathrm{Cu}, \mathrm{SiO}_{2}\end{array}$ & & $9.2(26.3)$ & - & $0.72(0.9)$ & & $\begin{array}{c}\text { N type. } \\
\text { Resistivity may } \\
\text { be influenced by } \\
\text { Cu between } \mathrm{Si} \\
\text { grains }\end{array}$ \\
\hline 89 & $\mathrm{SiO}_{2}$ & 4 & B & 1000 & $\mathrm{BaF} 2$ & - & $\begin{array}{c}0.065 \\
(0.186)\end{array}$ & $\sim 120$ & $4.0(5.0)$ & $8.38 \mathrm{~B}$ & GDMS \\
\hline 90 & graphite & 4.0 & MGSi & - & - & 15 & $0.23(0.66)$ & 12 & $5.8(7.2)$ & $8.045 \mathrm{~B}$ & Vacuum only \\
\hline 91 & $\mathrm{SiO}_{2}$ & 5.82 & B & 10 & $\mathrm{Re}$ & - & & & & & \\
\hline 92 & $\mathrm{SiO}_{2}$ & 12 & MGSi & 10 & $\operatorname{Re}$ & $\sim 25$ & & $\sim 19$ & & & $\begin{array}{l}\text { Resistivities } \\
\text { P to } N \text { type }\end{array}$ \\
\hline
\end{tabular}

\subsection{PHASE II PROJECT OBJECTIVES}

Based on the results from the Phase I program, as well as literature data, it was realized that better vacuum levels would be needed to achieve efficient vacuum refining of $\mathrm{P}$ and Al. B was not considered a likely candidate for vacuum refining, because of its low volatility, but modeling suggested that $\mathrm{P}$ and $\mathrm{Al}$ could be removed much faster than had been observed during the Phase I program with modest improvements in vacuum.

Another goal of the Phase II program was to quantify the effects of vacuum level, temperature, mass and surface-area to-volume ratio on the rate of removal of P and Al. 
Final Report for DOE SBIR Phase II, Contract Number DE-FG02-04ER83928

Crystal Systems, Inc., 27 Congress Street, Salem, MA 01970

In addition to the $\mathrm{P}$ removal, the use of additives led to further developments that gave rise to slagging. This was motivated by an ongoing need to develop further boron refining technology, based on operations by Dow Corning using the previously developed boron refining technology.

Another major area of technology that the Phase I program showed would be useful for upgrading MG silicon was the area of reusable crucible, as well as lower cost crucibles that could be used in a refining environment.

\subsection{VACUUM REFINING}

\subsection{Improvements}

During the Phase I program, it was shown that it was not possible to achieve low enough vacuum levels using silica crucibles to effectively remove $\mathrm{P}$ and Al. By using crucibles that do not have a gaseous reaction product with molten silicon, adequate vacuum levels were achieved to remove $\mathrm{P}$. Even with the proper crucible, only the best vacuum levels produced good results, and it was realized that for the Phase II program, a better vacuum system would be needed. To do this the furnace would need to be overhauled and sealed more robustly than had been done.

This was accomplished by installing a large diameter (4") connection to a roots blower pump, replacing many sealing parts for the furnace, adding a 4 " diffusion pump, and finding and fixing a small water shell leak. In addition to these improvements, a thorough a reworking of the procedures for backfilling, opening, and closing the reactor, and attention to detail in cleaning the furnace and performing timely bakeouts were also instrumental in decreasing the time it took to reach sufficient vacuum levels.. This resulted in maintaining the furnace in a "dry" state and allowed ultimate vacuums to be reached much more rapidly. Without this it would have been difficult to quantify the effects of vacuum, as they would have progressed to their best value far too slowly. The reduced pressures were achieved rapidly, allowing sampling of the $\mathrm{Si}$, followed by a timed hold at a known vacuum, in order to quantify the effect of other variables besides vacuum on the rate of removal. After making improvements to the vacuum system, the ultimate vacuum that could be achieved improved from 243 microbars during a phosphorus removal experiment during Phase I to as low as 22 microbars during P removal experiments during Phase II. This allowed a critical threshold to be crossed which greatly accelerated the rate of $\mathrm{P}$ and $\mathrm{Al}$ removal.

\section{$\underline{4.2 \text { Results }}$}

Another goal of the SBIR was to scale up the P removal results from the Phase I program to larger charge sizes, and to determine the effects of surface area, mass, $T$ and vacuum levels on the removal rate. The results of these tests are shown in Table 3 and Table 4. The rates are expressed in terms of half-lives, which assumes that during an experiment with all variables held constant, the rate of removal would be directly dependent on the concentration. In that case, the half-life is the time needed to reduce the P level to half its original value. Data were collected on surface area to volume ratios (depth of melt), the T, the reactor pressure, and the mass of silicon. Samples were taken after known lengths of time and the samples were analyzed by glow discharge mass spectroscopy. 
Final Report for DOE SBIR Phase II, Contract Number DE-FG02-04ER83928

Crystal Systems, Inc., 27 Congress Street, Salem, MA 01970

Table 3. P removal by vacuum.

\begin{tabular}{|c|c|c|c|c|c|c|}
\hline Run No. & $\begin{array}{c}\text { Si mass } \\
(\mathrm{kg})\end{array}$ & Initial P & Final P & $\begin{array}{c}\% \mathrm{P} \\
\text { Reduction }\end{array}$ & $\begin{array}{c}\text { Best P } \\
\text { half-life } \\
(\mathrm{hrs})\end{array}$ & Comments \\
\hline MG3-87 & 4.82 & 0.39 & 0.065 & $95 \%$ & 44.8 & \\
\hline MG3-90 & 4.0 & 15 & 0.23 & $95 \%$ & 13.6 & \\
\hline MG3-106 & 0.73 & 9 & 0.45 & $95 \%$ & 5.03 & \\
\hline MG3-107 & 0.73 & 7.8 & 0.35 & $96 \%$ & 4.95 & \\
\hline MG3-108 & 0.75 & 8.2 & 0.15 & $98 \%$ & 4.16 & \\
\hline MG3-119 & 27 & 19 & 4.5 & $76 \%>$ & 5.6 & Furnace shut down \\
\hline MG3-121 & 33.8 & 10 & 0.8 & $92 \%>$ & 14.7 & \\
\hline MG3-124 & 27 & 15 & 0.8 & $94 \%>$ & 11.4 & Process upset \\
\hline MG3-126 & 17 & 14 & 0.6 & $96 \%>$ & 5.4 & \\
\hline MG3-128 & 40 & 20 & 1.71 & $91 \%$ & 13 & \\
\hline MG3-131 & 36.5 & 14 & 2.4 & $83 \%$ & 14 & Furnace reconfiguration \\
\hline MG3-140 & 37.5 & 14 & 0.225 & $98 \%$ & 10.1 & Dow Corning supplied material \\
\hline $218 \mathrm{HS}$ & 35 & 26.2 & 15.71 & $40 \%$ & 32.5 & Modified process, different furnace \\
\hline
\end{tabular}

Table 4. Selected P removal experiments that permitted correlation of data to model rates.

\begin{tabular}{|l|c|c|c|c|c|c|c|c|c|c|}
\hline Run & $\begin{array}{c}\text { duration } \\
\text { (hrs.) }\end{array}$ & $\begin{array}{c}\text { P initial } \\
\text { (ppmw) }\end{array}$ & $\begin{array}{c}\text { P final } \\
\text { (ppmw) }\end{array}$ & $\begin{array}{c}\text { half-life } \\
\text { (hours) }\end{array}$ & $\mathrm{T}(\mathrm{C})$ & $\begin{array}{c}\text { Reactor } \\
\text { Pressure } \\
\text { (millibars) }\end{array}$ & $\begin{array}{c}\text { cm } \\
\text { depth }\end{array}$ & $\begin{array}{c}\text { mass } \\
\text { (kg) }\end{array}$ & $\begin{array}{c}\text { Model } \\
\text { half-life }\end{array}$ & $\begin{array}{c}\text { ratio model } \\
\text { to } \\
\text { measured }\end{array}$ \\
\hline MG3-90 & 44.0 & 15 & 1.6 & 13.6 & 1585 & 0.421 & 4.0 & 4.0 & 4.6 & 3.0 \\
\hline MG3-90 & 23.1 & 1.6 & 0.7 & 18.0 & 1585 & 0.180 & 4.0 & 4.0 & 3.3 & 5.5 \\
\hline MG3-121 & 4.7 & 10 & 8.4 & 18.7 & 1500 & 0.051 & 7.9 & 33.8 & 4.2 & 4.5 \\
\hline MG3-121 & 16.5 & 8.4 & 5.5 & 27.0 & 1500 & 0.040 & 7.9 & 33.8 & 3.6 & 7.5 \\
\hline MG3-121 & 22.7 & 5.5 & 1.9 & 14.8 & 1500 & 0.039 & 7.9 & 33.8 & 5.5 & 2.7 \\
\hline MG3-124 & 2.4 & 15 & 13.0 & 11.4 & 1500 & 0.068 & 16.4 & 27.0 & 4.9 & 2.3 \\
\hline MG3-124 & 80.0 & 13 & 0.3 & 20.1 & 1500 & 0.033 & 16.4 & 27.0 & 6.9 & 2.9 \\
\hline MG3-126 & 17.5 & 14 & 1.5 & 5.4 & 1500 & 0.036 & 4.5 & 17.0 & 1.7 & 3.1 \\
\hline MG3-126 & 22.2 & 1.5 & 0.3 & 8.8 & 1500 & 0.034 & 4.5 & 17.0 & 1.7 & 5.2 \\
\hline MG3-128 & 4.2 & 20 & 16.0 & 13.0 & 1425 & 0.045 & 10.7 & 40.0 & 4.5 & 2.9 \\
\hline MG3-128 & 48.6 & 16 & 1.7 & 15.1 & 1425 & 0.035 & 10.7 & 40.0 & 4.1 & 3.7 \\
\hline MG3-131 & 16.0 & 14 & 6.5 & 14.5 & 1425 & 0.032 & 8.5 & 36.5 & 3.6 & 4.0 \\
\hline MG3-140 & 48.0 & 14 & 0.5 & 10.2 & 1500 & 0.030 & 8.7 & 37.5 & 3.7 & 2.8 \\
\hline
\end{tabular}


Figure 2 shows an example of one such experiment. During a single run, several segments were performed. During one segment the charge was held under vacuum under constant temperature and vacuum level for a set period of time. After this time, the furnace was backfilled with Ar, and a liquid sample of the silicon charge was taken, to define the $\mathrm{P}, \mathrm{Al}$ etc. concentration at that point. Then the furnace was put back under vacuum and the furnace was held at a different set of conditions. This process was repeated several times on several runs. An example of these data for $\mathrm{P}$ and $\mathrm{Al}$ are shown in Figure 2. The first sample represents the initial composition of the charge, taken as a liquid sample after the charge had melted. The second sample was from the liquid after being held for a segment 1 , the third after segment 2. The final two samples represent different parts of the ingot, from near the top and bottom, to quantify the range of conditions in the ingot due to directional solidification. An example of such an ingot after the run is shown in Figure 3.

Improvements made to the vacuum after MG3-87 (44 hour half-life) led to better half-lives on MG390 (13.6 hour half-life) and to even better half-lives in the Phase II program experiments. Even more importantly, the charges were scaled up from $4 \mathrm{~kg}$ in Phase I to $40 \mathrm{~kg}$ in Phase II, with even better half-lives than the smaller charges. These improvements are reflected directly in the values of the reactor pressure in Table 4.

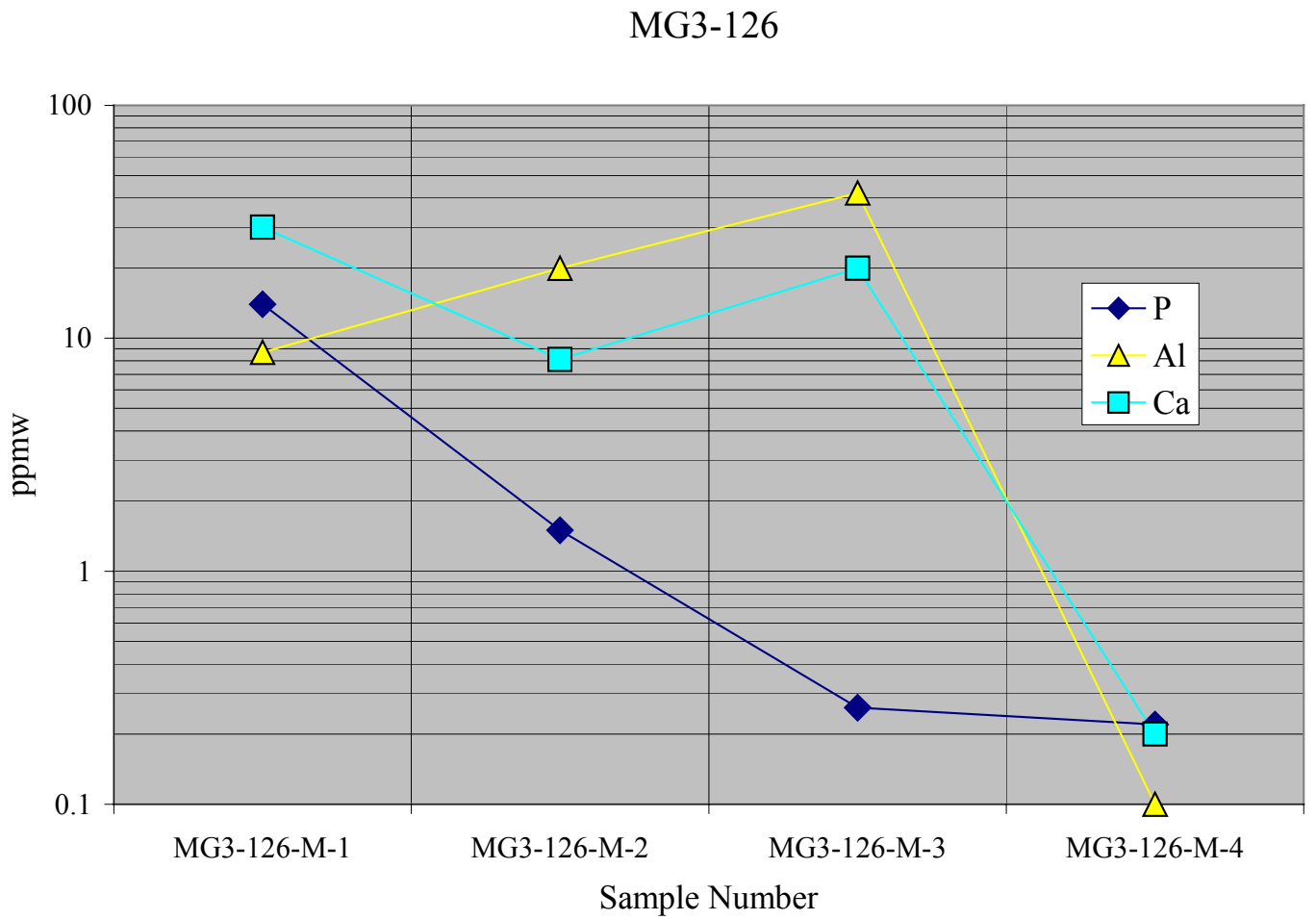

Figure 2. Removal of $\mathrm{P}, \mathrm{Ca}$ and $\mathrm{Al}$ during a vacuum run. The vertical axis shows the concentration in ppmw, on a logarithmic scale. The horizontal axis shows the individual sample numbers corresponding to segments or else the final ingot samples. This run contained $17 \mathrm{~kg}$ of silicon and showed a final analysis of 0.075 ppmw $\mathrm{P}$ - from a starting composition of 14 ppmw $\mathrm{P}$. 
Final Report for DOE SBIR Phase II, Contract Number DE-FG02-04ER83928

Crystal Systems, Inc., 27 Congress Street, Salem, MA 01970

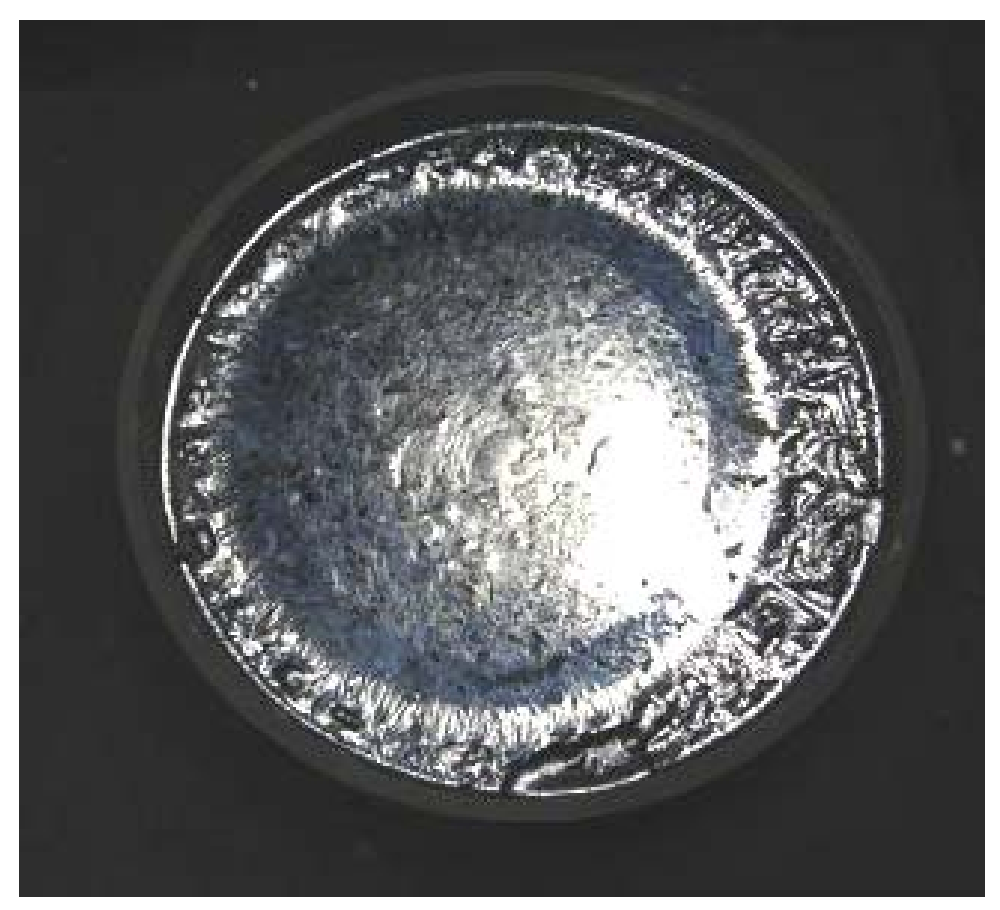

Figure 3. An ingot after vacuum removal showing clean surface. This ingot was 18 " in diameter and weighed $36.5 \mathrm{~kg}$.

\subsection{Models and Predictions}

These data were correlated with a model based on thermodynamic data and models from the literature ${ }^{24-27}$. Not all of the data collected permitted such correlations, due to loss of data on vacuum, poor temperature control, or uncertainty in other parameters that would vary during the run. The data that were suitable for comparison are shown in Table 4. The model successfully explains most of the variation in the observed half-lives, although our results were approximately a factor of 3 worse than the model. This in all likelihood reflects the poor geometry for $\mathrm{P}$ removal in the current furnace design. This model was corrected based on the data from this program, and the predictions of the model of the effect of reducing the vacuum even further is shown in Figure 4. The result is clearly seen that the vacuum levels, though improved, are just outside the range that much faster removal will be possible. With a purpose-built furnace or ladle, it is believed that such improvements in vacuum are readily achievable and that vacuum refining can be scaled up to be a cost effective technique for $\mathrm{P}$ and Al removal. 
Final Report for DOE SBIR Phase II, Contract Number DE-FG02-04ER83928

Crystal Systems, Inc., 27 Congress Street, Salem, MA 01970

Phase II

Half life (hours) vs Reactor Pressure (mbar)

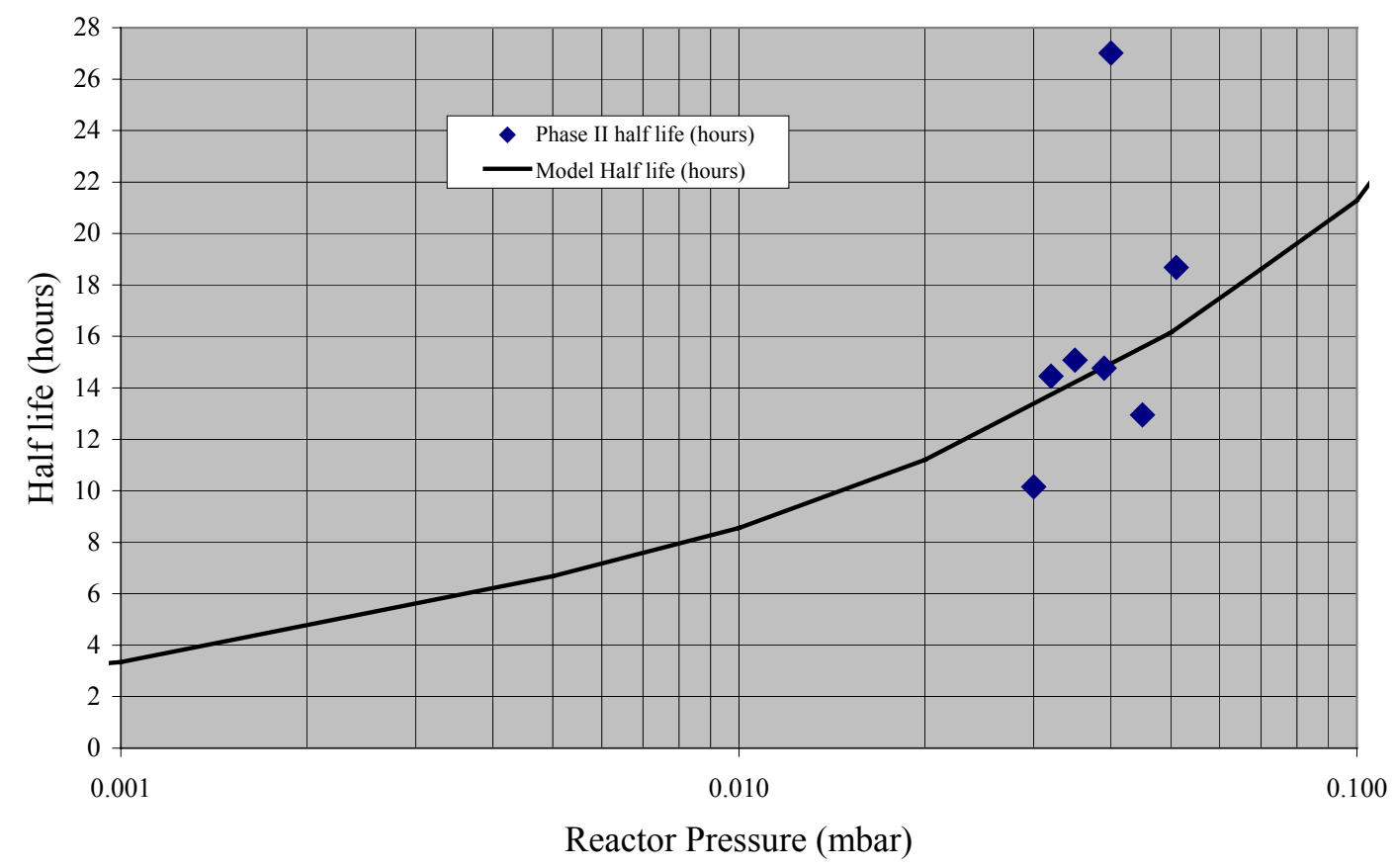

Figure 4. Effect of pressure on the phosphorus removal rate. The $X$ axis shows the pressure (in millibar) of the furnace, and the $\mathrm{Y}$ axis shows the $\mathrm{P}$ removal rate expressed as a half life (in hours.) The data are from Phase II work done after vacuum improvements and are all of similar mass, temperature, and depth of melt. The curve shows the predictions of the model based on our data and literature data. This figure clearly shows that a lower pressure would result in much faster refining of the P.

\subsection{Cold Finger}

During the vacuum tests, it was realized that the $\mathrm{P}$ path out of the furnace was probably a major bottleneck to the removal. It was attempted to provide the $\mathrm{P}$ with a sink in the hot zone, to shorten the path length and thus the chance for $\mathrm{P}$ to be recaptured by the melt. To this end, a tungsten "cold finger" was inserted into the hot zone. This consisted of a close ended tungsten tube, with a moly injection tube inside. The injection tube was used to pass Ar gas through, and thus cooling the cold finger. The results did not indicated a major effect on $\mathrm{P}$ reduction rates. One such heat exchanger is shown after use in Figure 5. The cold finger was successful in attracting and collecting excess silicon that was evaporating from the melt, and this silicon was highly enriched in P, indicating that this technique may be worth pursuing in a more optimal furnace geometry. 
Final Report for DOE SBIR Phase II, Contract Number DE-FG02-04ER83928

Crystal Systems, Inc., 27 Congress Street, Salem, MA 01970

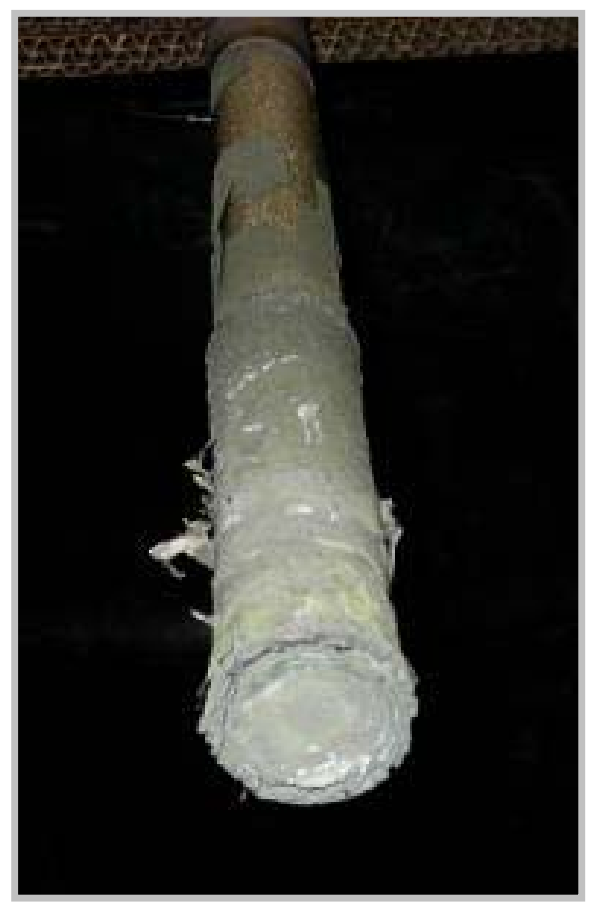

Figure 5. The cold finger after several tests. The deposits on the cold finger were found to be highly enriched in $\mathrm{P}$, but the overall effect was not improved enough.

\subsection{Vacuum and Directional Solidification}

Another factor found to be very interesting was the effects of combining directional solidification with vacuum removal. The effect became apparent during resistivity checks on ingots that indicated no increase in $\mathrm{P}$ during the ingot growth. This was due to the removal of $\mathrm{P}$ by vacuum from the residual liquid while the ingot was growing. In fact, the directional solidification has a synergistic effect with the vacuum removal, because as the solidification progresses it tends to concentrate the $\mathrm{P}$ in the remaining liquid. The more concentrated $\mathrm{P}$ is then easier to remove by vacuum because it will have a higher vapor pressure. The net result is that a significant decrease in overall $\mathrm{P}$ in the ingot can be achieved by performing the directional solidification in vacuum. This effect is demonstrated by the run shown in Figure 6.

A particular benefit of this effect will be realized if the reusable crucible can be demonstrated to work to grow ingots in vacuum conditions. This would allow leveling of the $\mathrm{P}$ content in an ingot during growth, which would have distinct advantages in making more consistent cells from various parts of an ingot. 
Final Report for DOE SBIR Phase II, Contract Number DE-FG02-04ER83928

Crystal Systems, Inc., 27 Congress Street, Salem, MA 01970

MG3-119

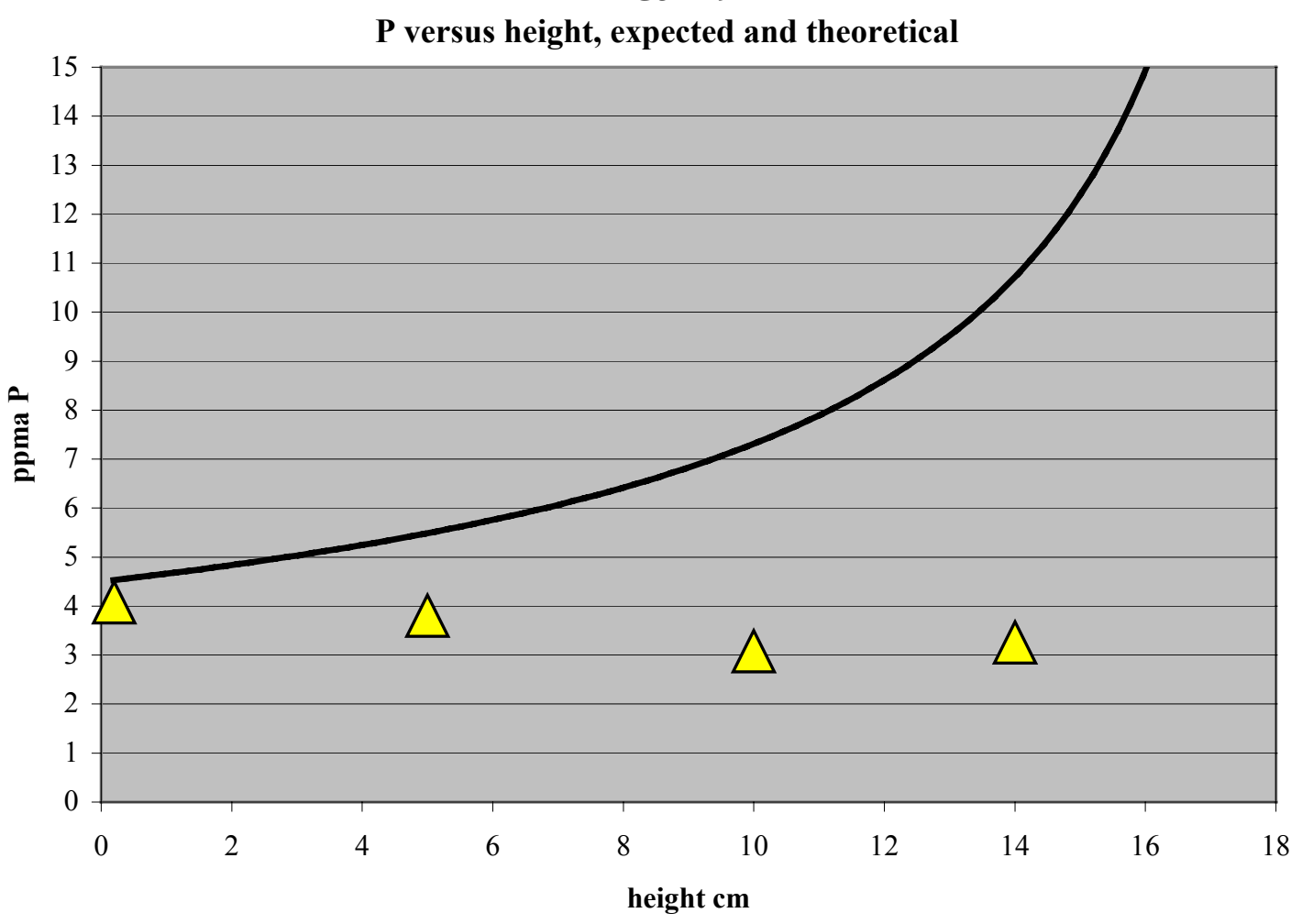

Figure 6. Measured $\mathrm{P}$ versus ingot height versus model $\mathrm{P}$ versus ingot height. It is particularly apparent from this figure that there was continued removal of $\mathrm{P}$ during segregation. The curve shows the expected value of $\mathrm{P}$ during the growth of the ingot due to segregation effects, which is normally followed quite closely. The triangles represent actual analyses from the ingot at the given height. Rather than increasing, the $\mathrm{P}$ content decreases slightly, indicating very effective removal during directional solidification.

\subsection{CRUCIBLE DEVELOPMENTS}

Molten silicon reacts with standard oxide crucibles to produce gaseous byproducts, which can eliminate the possibility of vacuum refining. Thus, it was necessary to develop a crucible that would not produce gaseous reaction products for vacuum reduction. In addition to this, another benefit to this development could be the realization of a reusable crucible for ingot growth technology, greatly reducing the costs of producing silicon. Both of these goals were attempted in developments on crucibles. The approaches to reusable crucibles can be broken down in three main areas - liners, coatings, and crucible material itself. During the course of the SBIR program, 28 separate experimental runs were performed testing various combinations of crucible materials, liners, and coatings. Most of these runs contained several individual experimental arrangements of crucibles, liners, and coatings. In addition to these, 37 conditioning runs were performed, most of which contained materials for further testing on which conditioning experiments were performed. These runs are listed in Table 5. 
Final Report for DOE SBIR Phase II, Contract Number DE-FG02-04ER83928

Crystal Systems, Inc., 27 Congress Street, Salem, MA 01970

Table 5. Coatings, liners and crucible development runs from Phase II.

\begin{tabular}{|c|c|c|c|}
\hline Run & $\begin{array}{c}\text { Run start } \\
\text { date }\end{array}$ & Run finish date & Crucibles/test \\
\hline MG3-109 & $04 / 25 / 06$ & $05 / 03 / 06$ & 1 liner \\
\hline MG3-110 & $06 / 07 / 06$ & $06 / 12 / 06$ & 1 liner \\
\hline MG3-111 & $07 / 21 / 06$ & $07 / 27 / 06$ & 2 liners and coatings \\
\hline MG3-112 & 08/06/06 & $08 / 14 / 06$ & 1 test piece, 1 encapsulant \\
\hline MG3-113 & $08 / 22 / 06$ & $08 / 25 / 06$ & 1 encapsulant, 1 liner plus encapsulant \\
\hline MG3-115 & $09 / 20 / 06$ & $09 / 23 / 06$ & 2 liners + coatings \\
\hline MG3-116 & $10 / 02 / 06$ & $10 / 06 / 06$ & 1 encapsulant + liner \\
\hline MG3-117 & $10 / 26 / 06$ & $10 / 30 / 06$ & 2 coatings \\
\hline MG3-118 & $11 / 03 / 06$ & $11 / 06 / 06$ & 1 liner + coating, 1 coating, 4 coated liner test pieces \\
\hline MG3-120 & $11 / 28 / 06$ & $11 / 30 / 06$ & 1 liner 1 coating \\
\hline MG3-122 & $12 / 11 / 06$ & $12 / 12 / 06$ & 2 coatings and liners \\
\hline MG3-123 & $12 / 21 / 06$ & $12 / 23 / 06$ & 1 coating and liner \\
\hline MG3-125 & $01 / 25 / 07$ & $01 / 29 / 07$ & 2 coatings and liners \\
\hline MG3-127 & $02 / 05 / 07$ & $02 / 08 / 07$ & 2 coatings and liners \\
\hline MG3-129-HEM1 & $02 / 12 / 06$ & $02 / 15 / 07$ & 2 coatings and liners \\
\hline MG3-130-HEM1 & $02 / 22 / 07$ & $02 / 26 / 07$ & 2 coatings and liners \\
\hline MG3-132-HEM1 & $03 / 08 / 07$ & $03 / 12 / 07$ & 2 coatings and liners \\
\hline MG3-135-HEM1 & $03 / 22 / 07$ & $03 / 26 / 07$ & 2 coatings \\
\hline MG3-138-HEM1 & $04 / 16 / 07$ & $04 / 19 / 07$ & 2 coatings \\
\hline MG3-139-HEM1 & $04 / 23 / 07$ & $04 / 26 / 07$ & 2 coatings \\
\hline MG3-142 & $05 / 10 / 07$ & $05 / 14 / 07$ & 1 coating \\
\hline MG3-143 & $05 / 17 / 07$ & $05 / 21 / 07$ & 1 coating \\
\hline MG3-147 & $06 / 06 / 07$ & $06 / 08 / 07$ & 1 coatings \\
\hline MG3-149 & $06 / 15 / 07$ & $06 / 18 / 07$ & 1 coatings \\
\hline MG3-151 & $06 / 20 / 07$ & $06 / 25 / 07$ & 1 coatings \\
\hline MG3-153 & $07 / 02 / 07$ & $07 / 03 / 07$ & 1 liner \\
\hline $215 \mathrm{HS}$ & $06 / 26 / 07$ & $07 / 02 / 07$ & 1 coating \\
\hline $216 \mathrm{HS}$ & $07 / 16 / 07$ & $07 / 19 / 07$ & 1 liner \\
\hline $217 \mathrm{HS}$ & $07 / 25 / 07$ & $07 / 30 / 07$ & 1 liner \\
\hline
\end{tabular}


Final Report for DOE SBIR Phase II, Contract Number DE-FG02-04ER83928

Crystal Systems, Inc., 27 Congress Street, Salem, MA 01970

As discussed earlier, it is desirable to have an appropriate crucible that can be used for vacuum and other refining of MG silicon in the molten state. The physics of removal of volatile impurities including $\mathrm{P}$ have been known but the problem was materials and engineering to have a system to achieve it. A significant hurdle is the availability of a crucible material that can be used in this step, and in combination with other refining steps for other impurities. The promising results in Phase I for purification of $\mathrm{P}, \mathrm{B}$ and Al under vacuum could only be achieved because development of a crucible was successful. Therefore, further development of this task is essential for the overall program. This crucible has to meet the following criteria:

- Use temperature in excess of $1600^{\circ} \mathrm{C}$

- Ability to contain molten $\mathrm{Si}$

- Non-contaminant to $\mathrm{Si}$

- Low-cost, commercially available

- Compatible with liners/coatings that can make it reusable.

Three broad approaches were tried: liners, coatings, and crucible materials. During the course of this study, it was discovered that the processing steps taken to prepare these materials were very important, and in some cases, as important as the choice of materials itself. After developing techniques to use the liners and the coatings separately, the liners and coatings were combined on a number of runs to take advantage of both techniques. Finally, alternate crucibles were tried with coatings and liners. Several examples of coatings tests are shown below.

\section{$\underline{5.1 \text { Coatings }}$}

Coatings were applied to various crucibles and substrates using spray coatings or paintings with standard techniques. These were dried, baked, and in some cases processed during a separate furnace run. Process parameters included heating rate, $\mathrm{T}$, gas and pressure. An example of a crucible with a coating is shown in Figure 7. In addition to the crucibles, various coupons of potential crucible materials were made, and they were treated with various coatings and processed. Sometimes the processing was included with other runs or bakeouts. An example of such a coupon is shown in Figure 8 . 
Final Report for DOE SBIR Phase II, Contract Number DE-FG02-04ER83928

Crystal Systems, Inc., 27 Congress Street, Salem, MA 01970

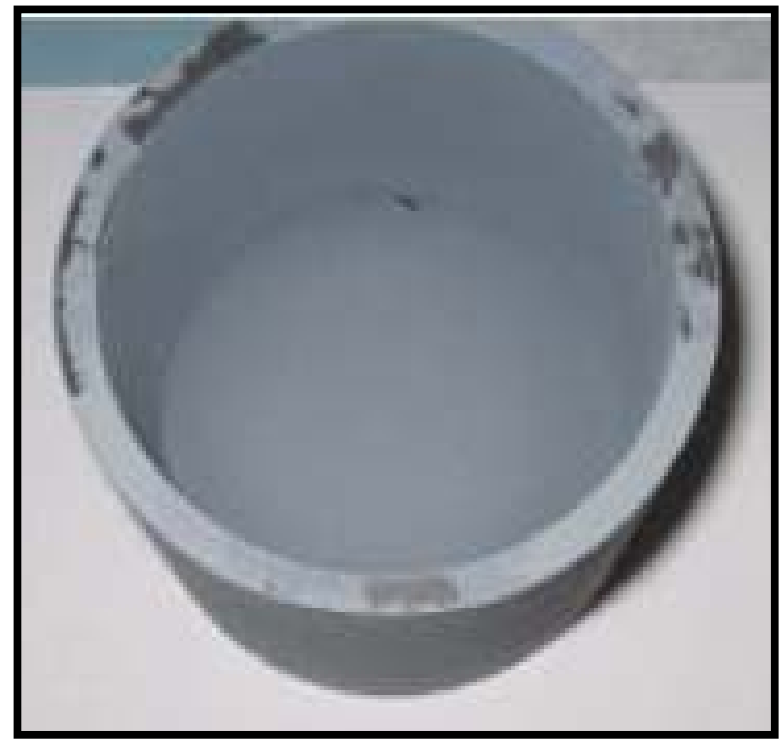

Figure 7. Coated graphite crucible. Used in MG3-107. It was found that the adherence of the coatings could be affected by rate of temperature ramping during the firing, as well as the atmosphere, and the previous processing of the crucible. A standard approach was developed that allowed reproducible coatings to be applied that allowed the crucible to be reused. If the process was not followed, the coating was uneven and not always suitable.

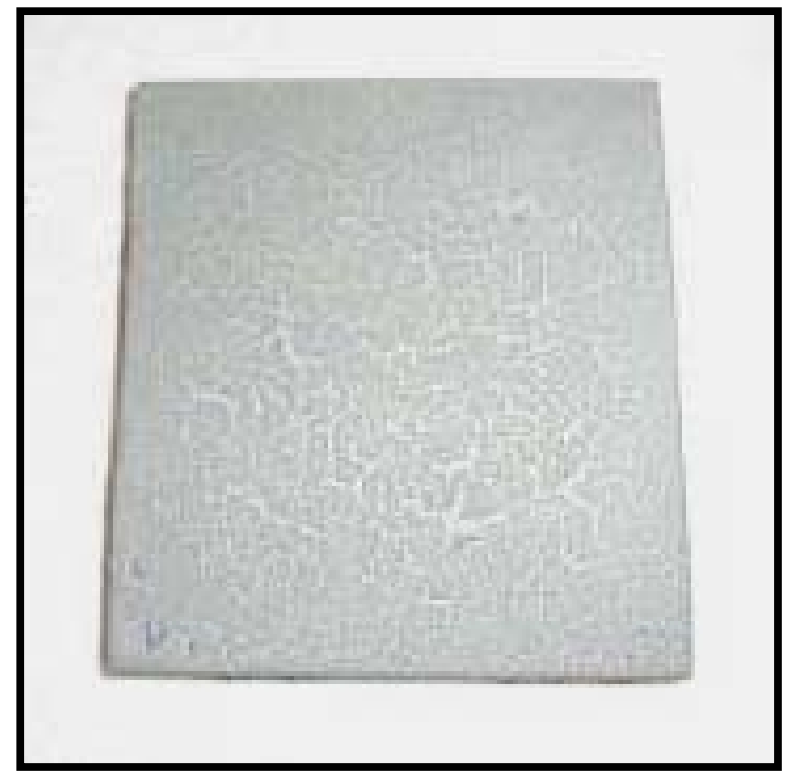

Figure 8. 4"x4" coupon coated and processed in a normal experimental run. Coating was cracked but adhered. It was discovered that the rates at which the various coatings were heated and baked impacted their ability to adhere and form continuous sheets. 
Final Report for DOE SBIR Phase II, Contract Number DE-FG02-04ER83928

Crystal Systems, Inc., 27 Congress Street, Salem, MA 01970

\section{$\underline{5.2 \text { Liners }}$}

During the course of this work, it became apparent that containing the silicon would be difficult. The silicon had a tendency to wick behind the various liners, and flow up and out of the crucible. This problem was overcome by using a combination of liners, coatings, and controlled gas environment. Two crucibles are shown in Figure 9 - one crucible with the silicon contained, and the other crucible where the silicon had all wicked out. After this development was accomplished reproducibly, the same approach was tried on lower cost crucibles. These showed that they could keep the silicon from contacting and reacting with the crucible. The benefit to this technology development is that crucibles may be chosen on the basis of their cost, and/or other parameters such as coefficient of thermal expansion. This would allow either much lower cost crucibles to be used in a sacrificial manner or, by engineering the thermal expansion of the crucible, could result in a crucible that will release silicon and thus could be reusable after refining.

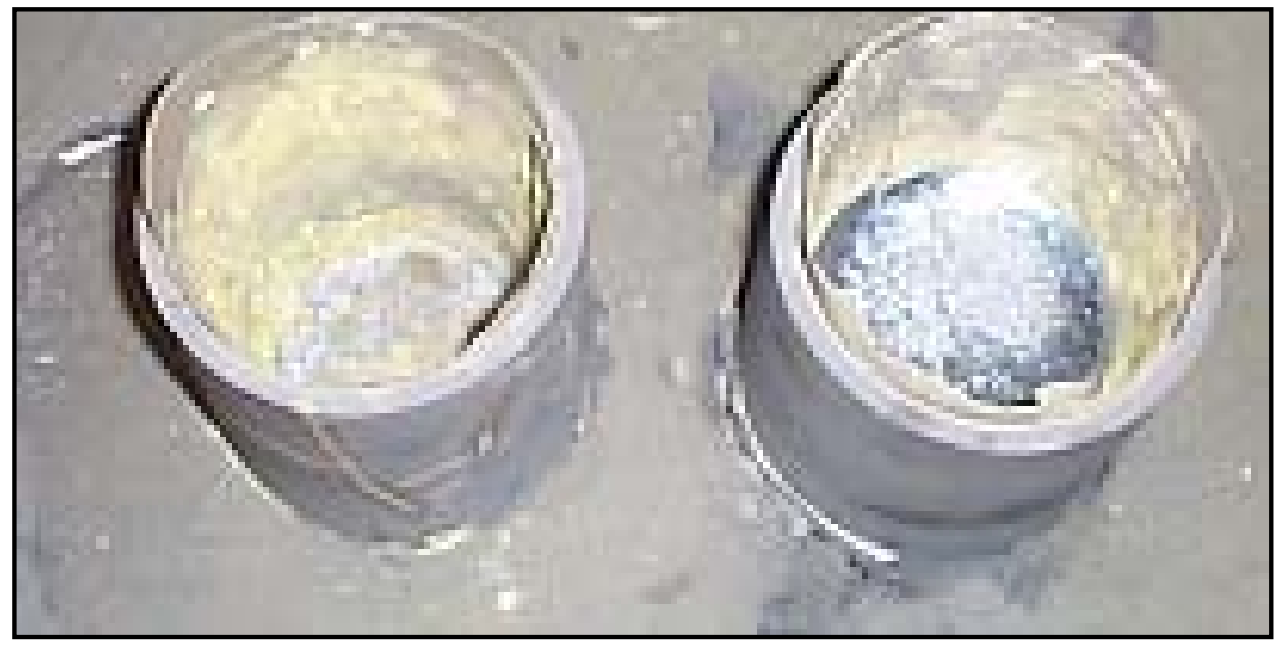

Figure 9. Liners in two crucibles. The crucible on the left has lost all of its silicon due to wicking. The crucible on the right contained its silicon under the exact same conditions.

\subsection{Reusable Crucibles}

One of the goals was to make a reusable crucible. This effort was successful, with the reusability being demonstrated several times on several different crucibles. Amongst these runs were three runs performed with the same crucible. Further experimentation with this crucible finally resulted in the silicon sticking, but it was clear that if the successful parameters had been used this crucible could have been reused very many times. The crucible showed no signs of degradation, and the ingots released easily and showed no problems associated with being grown in a used crucible. The reusable crucible was the product of a particular type of crucible, a pre-coating process, and a coating process. These process steps were simple and did not incur undue costs, and are easily translated to a commercial ingot-producing environment. The crucible and coating are compatible with producing ingots for $\mathrm{PV}$, and this result can translate into a reduced cost technique for making silicon ingots for PV. 


\subsection{SLAGGING}

One of the most significant results of the SBIR has been the development of a slagging approach to removal of $\mathrm{P}$ as well as $\mathrm{B}$ from silicon. The motivation was to develop an alternate technique for removing boron from $\mathrm{Si}$, initially. This slagging approach is an outgrowth of the additives work during Phase I, as well as thermodynamic modeling and literature surveys to find the most promising technique. Some of the results from the additives work during Phase I suggested some overlooked areas in slagging that would be worth investigating, and it involves several non-standard approaches to slagging. The results have been very encouraging.

Eleven experimental runs were performed involving slags, with many of the runs containing multiple crucibles containing different slag compositions. Because the slagging effect can produce its results so quickly, as well as for other operational issues, it was impossible to obtain initial liquid samples to establish the pre-slagging composition. Instead, well-characterized starting materials were used, and the average of many analyses was used as the initial composition. Many of the results showed such large reductions in boron and phosphorus that this uncertainty represents a relatively insignificant error in the percent removed.

The data from these slagging runs are shown in Table 6. The slagging approach was very effective for removing boron, by as much as $76 \%$ in one case. However, it was even more effective at reducing phosphorus - over $99 \%$ reduction being seen. Very effective reduction was seen in slagging runs MG3-133, MG3-146, MG3-148, MG3-154, and MG3-158. In all cases, when the combination of slag compositions and processing parameters were effective for boron, they were even more effective for phosphorus. It is also important to point out that these runs were much shorter than the vacuum runs, but achieved comparable results. This approach may not be incompatible with vacuum and there could very well be synergies in combining these techniques.

The slagging approach was hampered by an operability issue involving separation of the silicon and slag, but progress was made during the program. The order in which certain process steps were taken was found to ameliorate some of the effects. This work has been very promising, and it continues to be developed. Figure 10 shows a slab of a $20 \mathrm{~kg}$ charge that was treated by slagging.

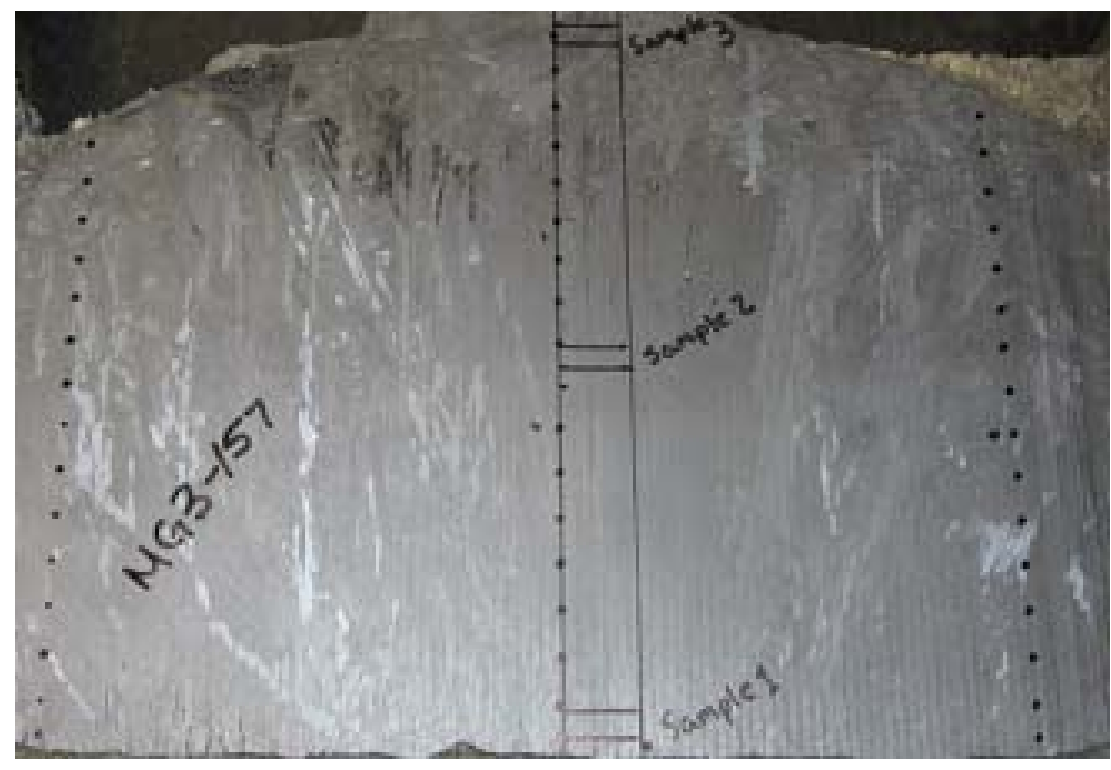

19
Figure 10. Results from slagging run MG3-157. This run contained $20 \mathrm{~kg}$ of upgraded metallurgical silicon. The locations for sample 1 and sample 3 are shown. These analyses are shown in Table 6. 
Final Report for DOE SBIR Phase II, Contract Number DE-FG02-04ER83928

Crystal Systems, Inc., 27 Congress Street, Salem, MA 01970

Table 6. Slagging results from the SBIR Phase II program.

\begin{tabular}{|l|c|c|c|c|c|c|c|c|c|}
\hline \multicolumn{1}{|c|}{ Run No. } & $\begin{array}{c}\text { B initial } \\
+/-3\end{array}$ & B final & $\begin{array}{c}\% \mathrm{~B} \\
\text { reduced }\end{array}$ & $\mathrm{KdB}$ & $\mathrm{P}$ initial & P final & $\begin{array}{c}\text { \%P } \\
\text { reduced }\end{array}$ & KdP & Slag/ Si \\
\hline MG3-133 & 19 & 4.6 & 76 & 5 & 26 & 0.10 & 99.62 & 452 & 0.57 \\
\hline MG3-141-1 & 19 & 18 & 5 & 0.1 & 26 & 9.5 & 63 & 2 & 0.86 \\
\hline MG3-141-2 & 19 & 8.7 & 54 & 2.1 & 26 & 11 & 58 & 2 & 0.57 \\
\hline MG3-141-3 & 19 & 12 & 37 & 1.2 & 26 & 14 & 46 & 2 & 0.48 \\
\hline MG3-144-1 & 19 & 12 & 37 & 0.9 & 26 & 17 & 35 & 1 & 0.67 \\
\hline MG3-144-2 & 19 & 12 & 37 & 0.9 & 26 & 17 & 35 & 1 & 0.67 \\
\hline MG3-144-3 & 19 & 10 & 47 & 1.4 & 26 & 22 & 15 & 0 & 0.67 \\
\hline MG3-145-2 & 19 & 12 & 37 & 0.9 & 26 & 9.2 & 65 & 3 & 0.67 \\
\hline MG3-146-1 & 19 & 8.5 & 55 & 1.2 & 26 & 8 & 69 & 2 & 1.00 \\
\hline MG3-146-2 & 19 & 5.7 & 70 & 2.3 & 26 & 2.6 & 90 & 9 & 1.00 \\
\hline MG3-148-1 & 19 & 7 & 63 & 3.0 & 26 & 1.0 & 96 & 46 & 0.57 \\
\hline MG3-150-1 & 19 & 8.7 & 54 & 2.6 & 26 & 2 & 92 & 26 & 0.45 \\
\hline MG3-150-2 & 19 & 11 & 42 & 0.5 & 26 & 13 & 50 & 1 & 1.45 \\
\hline MG3-152-1 & 19 & 16 & 16 & 1.7 & 26 & 4.4 & 83 & 43 & 0.11 \\
\hline MG3-152-2 & 19 & 14 & 26 & 3.2 & 26 & 5.9 & 77 & 30 & 0.11 \\
\hline MG3-154 & 19 & 9.5 & 50 & 1.7 & 26 & 1.8 & 93 & 23 & 0.57 \\
\hline MG3-155-1 & 19 & 15 & 21 & 0.7 & 26 & 5 & 81 & 10 & 0.41 \\
\hline MG3-155-2 & 19 & 15 & 21 & 0.7 & 26 & 10 & 62 & 4 & 0.41 \\
\hline MG3-157 & 19 & 12 & 37 & 2.3 & 26 & 8.7 & 67 & 8 & 0.25 \\
\hline
\end{tabular}

The major result from these slagging runs is that

1) the phosphorus and the boron could be both removed simultaneously in a single, short step to $99.6 \%$ and $76 \%$ of their original values, respectively, and

2) there were operability issues during the best results that required further work to overcome.

The benefits of a slagging approach over vacuum or gas refining is in the scale up of the process. Typically, slagging operations in steel-making take a very short time. However, vacuum and gas refining are essentially distillation processes, and the time required will generally scale with the mass of the material. However, slagging is a one-time equilibration between two phases, and this time can be independent of the mass of the system, as long as the relative surface areas of the two phases (the slag and the $\mathrm{Si}$ ) are kept high. This holds the promise for very rapid processing in large charges in a metallurgical environment. This process is very promising and the work continues at CSI. Other industry leaders have expressed interest in working cooperatively with CSI to finish the development of this process, and CSI is investigating these offers. 
Final Report for DOE SBIR Phase II, Contract Number DE-FG02-04ER83928

Crystal Systems, Inc., 27 Congress Street, Salem, MA 01970

\subsection{TECHNICAL AND ECONOMIC FEASIBILITY}

The main goals of the program have been met with some success at every stage. Removal of P and Al by vacuum has been demonstrated in large-scale melts. The improvements in the vacuum system and in furnace configuration have led to improvements in the refining rate. Furthermore, the data have been correlated into a predictive model. These results were made possible by the use of the proper crucibles, as well as the vacuum improvements made to the furnace. Surprising results are the degree to which the process is tolerant of vacuum degradation.

The crucible selection resulted in good compatibility between silicon and vacuum operations. Several crucibles were used multiple times, demonstrating the principle of reusability, and liners and coatings were developed that allowed the crucible to hold silicon.

The slagging has been the most interesting and unexpected development. Although work remains to be done on the scale up of this slagging system, the demonstration of removal of $>99 \%$ of the phosphorus and $76 \%$ of the boron indicates a new way of upgrading MG silicon may be in hand.

The removal of $\mathrm{P}$ by vacuum demonstrated a potentially commercially viable route to MG silicon upgrading. In conjunction with the B-removal technology this represents the basis for development of a commercial operation to upgrade $\mathrm{MG}$ silicon to $\mathrm{SoG} \mathrm{Si}$, using moist $\mathrm{H}_{2}$ boron refining, vacuum for removal of $\mathrm{P}, \mathrm{Al}$, and other volatile elements, and directional solidification to remove the rest.

However, in addition to this technology, the developments during the Phase II program have resulted in another viable approach that can be used either separately, or in conjunction with this prior technology to produce a faster approach to upgrading MG silicon. This is based on a modified slagging approach, in combination with other processing parameters.

Crystal Systems is currently investigating commercializing this technology. Capital requirements are being investigated, and further scoping experiments are ongoing at CSI expense. Discussions with industry representatives are ongoing. 
Final Report for DOE SBIR Phase II, Contract Number DE-FG02-04ER83928

Crystal Systems, Inc., 27 Congress Street, Salem, MA 01970

\subsection{CONCLUSION}

The lack of SoG silicon is stifling the rapidly growing PV industry. Looking beyond the short term crisis, even if current needs are met by the planned expansions by the polysilicon industry, will this industry commit to continue to grow at 35 to $45 \%$ to meet future demands? The threat of a replacement source of $\mathrm{Si}$, loss of subsidies for PV, the large capital costs involved, and the long time required to construct such plants militates against that scenario. The future supply of inexpensive SoG silicon is in doubt, whereas upgrading MG silicon would allow the infinite supply that might soon be necessary. The main elements preventing the upgrading are B and P. CSI previously developed a technology for B removal, therefore the initial focus of the Phase I and II programs was on reducing $\mathrm{P}$ (and $\mathrm{Al}$ ). Removal of $\mathrm{P}$ and $\mathrm{Al}$ by vacuum was demonstrated, and progress was made in developing an inexpensive alternative crucible plus liners and coatings for this processing. Thus, with the moist hydrogen boron removal process, and the vacuum removal of $\mathrm{P}$ and $\mathrm{Al}$, a proven technology set exists for upgrading MG silicon by metallurgical techniques.

However, drawbacks to the scalability of these technologies, especially B, required another removal technique. A non-standard slagging technique was developed that allowed for significant boron as well as $\mathrm{P}$ removal. This technique, being a slagging technique, is far more simply scaleable, and requires only a short interval to scavenge the impurities. Crucible linings and coatings have been developed that are low cost and allow the crucible to be potentially reused for ingot growth and refining.

There are still operability issues with this slagging technique, which are the subject of ongoing research. Recent results have been promising for solving the operability issues indicate progress being made in this direction. Other areas needing further development include environmental and safety issues during post run treatment of the slag, optimization of the slag compositions, processing parameters, and reusable crucible coatings and lining. The slag composition, process parameters and the reusable crucible must still be integrated to produce SoG silicon most cost effectively.

\section{REFERENCES}

1. Rogol, M. Porter C., Photon International, August 2007, pp. 112-118.

2. http://en.epochtimes.com/news/7-10-20/60994.html. Accessed on 1-1-2008.

3. Hunt, L. P., and Dosaj, V. D., Solar silicon via the Dow Corning Process, DOE/JPL-954559-78/6, 1978 .

4. Reuschel, K., and Schink, N., U.S. Patent 4,097,584 (June 1978).

5. Kotval, P. S., and Strock, H. B., U.S. Patent 4,195,067 (March 25, 1980).

6. Liaw, H. M., and Varker, C. J., U.S. Patent 4,200,621 (April 1980).

7. Pelosini, L., Parisi, A., and Pizzini, S., U.S. Patent 4,241,037 (Dec.23, 1980).

8. Dawless, R. K., U.S. Patent 4,246,249 (Jan. 20, 1981).

9. Dietl, J., and Wohlschlager, M., U.S. Patent, 4,304,763 (Dec. 8, 1981).

10. Dosaj V. D., and Hunt, L. P., U.S. Patent 4,247,528 (1981). 
Final Report for DOE SBIR Phase II, Contract Number DE-FG02-04ER83928

Crystal Systems, Inc., 27 Congress Street, Salem, MA 01970

11. Lindmayer, U.S. Patent 4,298,423 (Nov. 1981).

12. Dietl, J., Holm, C., and Sirtl, E., U.S. Patent, 4,312,850 (Jan. 26, 1982).

13. Helmreich, D., Sirtl E., and Zollner, T., U.S. Patent 4,312,700 (Jan. 1982).

14. Amick, J. A., Dismukes, J. P., Francis, R. W., Hunt, L. P., Ravishankar, P. S., Schneider, M., Matthei, K., Sylvain, R., Larsen K., and Schei, A., Proc. Symp. on Materials and New Processing Technologies for PVs, Proc. Vol. 83-11 (Electrochemical Soc., NJ, 1983) p. 67.

15. Shinghu, H., Otsuka, R., Tanimoto, S., and Toyoda, K., Process and Apparatus for Purifying Si, U.S. Patent 4,747,906 (May 31, 1988).

16. Schwirtlich, I., Lange H., and Kannchen, W., Process of Refining silicon and silicon Purified Thereby, U.S. Patent 4,837,376 (June 6, 1989).

17. Truitt, J. K., and Bawa, M. S., Method of silicon Purification, U.S. Patent 5,208,001 (May 4, 1993).

18. Yuge, N., Baba H., and Aratani, F., Method and Apparatus for Purifying Si, U.S. Patent 5,182,091 (Jan. 26, 1993).

19. Baba, H., Hanazawa, K., Yuge, N., Sakaguchi, Y., Terashima, H., and Aratani, F., Proc. E. C. PV Solar Energy Conf., Barcelona, Spain, 1997.

20. Khattak, C. P., Joyce, D. B., and Schmid, F., Upgrading $M G(M G)$ silicon for Use as SoG Feedstock, Proc. 28th IEEE PV Specialists Conference, Anchorage, Alaska, September, 2000.

21. Khattak, C. P., Joyce, D. B., and Schmid, F., Production of Low-Cost SoG (SoG) silicon Feedstock, Proc. 29th IEEE PV Spec. Conference, New Orleans, LA, May, 2002.

22. Khattak, C. P., Joyce, D. B., Schmid, F., Ciszek, T. F., Page, M. R., and Symko-Davies, M. I., SoG silicon for Solar Cell Applications, Proc. 17th European PV Solar Energy Conference and Exhibition, Munich, Germany, II, 1690-1693 (2001).

23. New Routes to Ultra-Low-Cost Solar-Grade silicon for Renewable Energy Generation, ATP Program, 2003.

24. K. Suzuki, K. Sakaguchi, T. Nakagiri, and N. Sano; J. Jpn. Inst. Met., 1990, vol. 54, pp. 161-167.

25. T. Ikeda and M. Maeda; Iron Steel Inst. Jpn. Int., 1992, vol. 32, pp. 635-642.

26. T. Miki, K. Morita, and N. Sano, Metallurg. and Materials Transactions B, 1996, vol. 27B, pp. 937-941

27. N. Yuge, K. Hanazawa, K. Nishikawa, and H. Terashima; J. Japan Inst. Metals, 1997 vol. 61, no. 10, pp. 1086-1093 